\title{
Killi Zeminin Kayma Mukavemetine Cam Lifi ve Su İçeriğinin Etkisi
}

\author{
Mehmet Fatih Yazıc1 $^{1 *}$, Ahmetcan Sungur ${ }^{2}$, Siddıka Nilay Keskin ${ }^{3}$

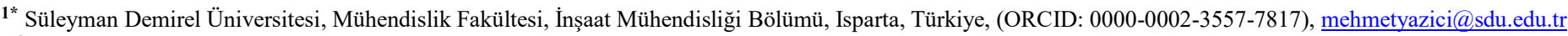 \\ ${ }^{2}$ Süleyman Demirel Üniversitesi, Fen Bilimleri Enstitüsü, İnşaat Mühendisliği Anabilim Dalı, 100/2000 YÖK Doktora Bursiyeri, Isparta, Türkiye, (ORCID: 0000- \\ 0001-6200-7601), ahmetcansungur@gmail.com \\ ${ }^{3}$ Süleyman Demirel Üniversitesi, Mühendislik Fakültesi, İņ̧aat Mühendisliği Bölümü, Isparta, Türkiye, (ORCID: 0000-0002-0367-943X), nilaykeskin@s,sdu.edu.tr
}

(1st International Conference on Applied Engineering and Natural Sciences ICAENS 2021, November 1-3, 2021)

(DOI: 10.31590/ejosat.1011840)

\begin{abstract}
ATIF/REFERENCE: Yazıc1, M.F., Sungur, A. \& Keskin, S.N. (2021). Killi Zeminin Kayma Mukavemetine Cam Lifi ve Su İceriğinin
\end{abstract} Etkisi. European Journal of Science and Technology, (28), 890-894.

\section{$\ddot{O} \mathbf{z}$}

Günümüzde yüksek mukavemetleri ve ekonomik olmaları nedeniyle rastgele dağıtılmış ayrık lifler ile zeminlerin güçlendirilmesi tekniği geleneksel zemin güçlendirme tekniklerine bir alternatif olarak öne çıkmaktadır. Mevcut çalışmada düşük plastisiteli kil zeminin kayma mukavemeti özellikleri üzerine cam lif ilavesi ve su içeriğinin etkileri araştırılmıştır. Bu amaç için üç farklı su içeriğginde; optimum su muhtevasında, altında ve üstünde $(\% 13, \% 15$ ve \%17) ve ağırlıkça üç farklı lif oranında $(\% 1,0, \% 1,5$ ve $\% 2)$ lif-kil karışımları hazırlanmışıtır. Hazırlanan numunelerin kayma mukavemetleri direkt kesme deneyinde incelenmiştir. Sonuç olarak en yüksek kohezyon, içsel sürtünme açısı ve kayma mukavemeti değerlerinin $\% 13$ ve $\% 15$ su muhtevası için sırasıyla $\% 1$ ve $\% 1,5$ lif içeriklerinde meydana geldiği gözlenmiştir. Buna karşıllk \%17 su muhtevası için optimum bir lif içeriğinin gözlenmediği, lif içeriğinin artması ile bu değerlerin sürekli arttığı sonucu elde edilmiştir. Ayrıca su içeriğinin artması ile lif-zemin arası adezyon etkisinin azalması sonucu kayma mukavemetinin azaldığı görülmüştür.

\section{The Effect of Glass Fiber and Water Content on Shear Strength of Clayey Soil}

\begin{abstract}
Today, the reinforcement with randomly distributed discrete fibers of soils stands out as an alternative to traditional soil reinforcement techniques due to their high strength and being economical. In the present study, the effects of glass fiber addition and the water content on the shear strength properties of low plasticity clay soil were investigated. For this purpose, fiber-clay mixtures were prepared at optimum water content (OWC), below OWC and above OWC (13\%, 15\% and 17\%) and three different fiber ratios (1.0\%, $1.5 \%$ and $2 \%$ ) by weight. Shear strengths of the prepared samples were investigated in direct shear test. As a result, it was observed that the highest cohesion, internal friction angle and shear strength values occurred at $1 \%$ and $1.5 \%$ fiber contents for $13 \%$ and $15 \%$ water content, respectively. On the other hand, it was concluded that an optimum fiber content was not observed for $17 \%$ water content, and these values increased continuously with increasing fiber content. In addition, it was observed that the shear strength decreased as a result of the reducing in the adhesion effect between the fiber and the soil with the increase in the water content.
\end{abstract}

Keywords: Glass fiber, Soil reinforcement, Water content, Direct shear test, Shear strength.

\footnotetext{
*Corresponding Author: mehmetyazici@sdu.edu.tr
} 


\section{Giriş}

Geoteknik mühendisliğinde, zeminlerin güçlendirilmesi üzerine literatürde birçok çözüm yolu önerilmektedir. Bu amaç için genellikle çimento ve kireç gibi kimyasal katkılar ile (kimyasal stabilizasyon) ve/veya geosentetik şeritler veya donatıların zemin içerisine yerleştirilmesi ile (mekanik stabilizasyon) zeminlerin güçlendirilmesi yoluna gidilmektedir. Kimyasal stabilizasyon malzemelerinin üretimi aşamasında yenilenemeyen kaynakların tüketimi ve çevreye verilen zararlar bu yöntemin dezavantajları olarak karşımıza çıkmaktadır. Mekanik stabilizasyon yöntemlerinde ise donatılar yatay ve/veya düşey yönde zemin içerisine yerleştirilmekte ve sadece güçlendirilmiş bölgelerde mukavemet artışı sağlanmakta, güçlendirme elemanlarının bulunmadığı düzlemler potansiyel zayıflık düzlemleri olarak kalmaktadır. Tüm bu nedenlerden ötürü günümüzde zeminlerin stabilizasyonunda kullanılabilecek ekonomik, çevre dostu ve sürdürülebilir alternatif malzemelere olan ihtiyaç artmaktadır. Yeterli mukavemetleri ve ekonomik olmalarından dolayı son zamanlarda rastgele dağıtılmış doğal ve sentetik lifler ile zeminlerin stabilizasyonu araştırma konusu olmuştur. Rastgele dağıtılmış ayrık lifler ile güçlendirilmiş zeminlerde, geleneksel mekanik stabilizasyon yöntemlerinde meydana gelen potansiyel zayıflık düzlemleri oluşturulmadan izotropik mukavemet artışı sağlanmaktadır (Gray ve Maher 1989, Maher ve Gray 1990, Yetimoğlu ve Salbaş 2003, Estabragh vd. 2011, Anagnostopoulos vd. 2013). Literatürde rastgele dağıtılmış lifler ile zeminlerin güçlendirilmesi tekniği üzerine yapılan çalışmalardan bazıları aşağıda verilmiştir.

Baruah (2015), 10 mm uzunluğunda ve ağırlıç̧a \%0,5-1,5 içeriklerinde cam lif ile güçlendirdiği kırmızı kilin serbest basınç mukavemetinin lif içeriğinin artması ile arttığını belirtmiştir. Saha ve Bhowmik (2018), kum-kil karışımının kayma dayanımı özellikleri üzerine \%0,5-1,5 içeriğinde cam lif ilavesinin ve su muhtevasının etkilerini araştırmışlar ve kayma dayanımı kazanımı açısından \%1 lif içeriğinin optimum değer olduğunu ifade etmişlerdir. Asadollahi ve Dabiri (2017), $10 \mathrm{~mm}$ uzunluğunda ve \%0,2-1 miktarlarında cam lif ile güçlendirdikleri kil zeminin dayanımında en yüksek artışın \%0,8 lif içeriğinde meydana geldiğini belirtmişlerdir. Ayrıca lif takviyesi ile zeminin daha sünek bir davranış sergilediğini ifade etmişlerdir. Abdeldjouad vd. (2019), çalışmalarında zemin stabilizasyonunu sağlayabilmek için cam lifler ile birlikte yakıt külü takviyeli palmiye yağını kullanmışlar ve cam lif oranının $\% 3$ ve $\% 3$ 'ten büyük olduğu durumlarda gerilme-şekilde değiştirme davranışında iyileşme gözlemlemişlerdir.

Literatürde düşük plastisiteli kil zeminin kayma mukavemeti üzerine cam lifi ilavesi ve su içeriğinin etkilerinin incelendiği çok fazla çalışma bulunmamaktadır. $\mathrm{Bu}$ nedenle bu çalışma kapsamında, kil zemin numunesi içerisine, zeminin kuru ağırlığının ağırlıkça \%1, \%1,5 ve \%2 oranlarında cam lifi rastgele bir şekilde ilave edilerek deney numuneleri hazırlanmıştır. Ayrıca cam lif ile birlikte su içeriğinin zeminin kayma mukavemeti üzerine etkisini gözlemlemek için, optimum su içeriğinde (OSİ) (\%15) ve OSİ \pm (\%13 ve \%17) olmak üzere aynı cam lif oranlarında da deney serileri hazırlanmıştır. Hazırlanan numuneler direkt kesme deneyine tabi tutularak, kohezyon, içsel sürtünme açısı ve kayma mukavemeti değerlerinin değişimi incelenmiştir.

\section{Materyal ve Yöntem}

\subsection{Malzemeler}

$\mathrm{Bu}$ çalışma kapsamında kullanılan kil zemin, Burdur ilinin Kemer ilçesine bağlı Akçaören köyünden alınmıştır. Kil zemine ait granülometri eğrisi ile zeminin özellikleri sırasıyla Şekil 1 ve Tablo 1'de verilmiştir. Yapılan deneyler sonucunda Birleştirilmiş Zemin Sınıflandırma Sistemi’ne göre zeminin sınıfı düşük plastisiteli kil (CL) olarak belirlenmiştir.

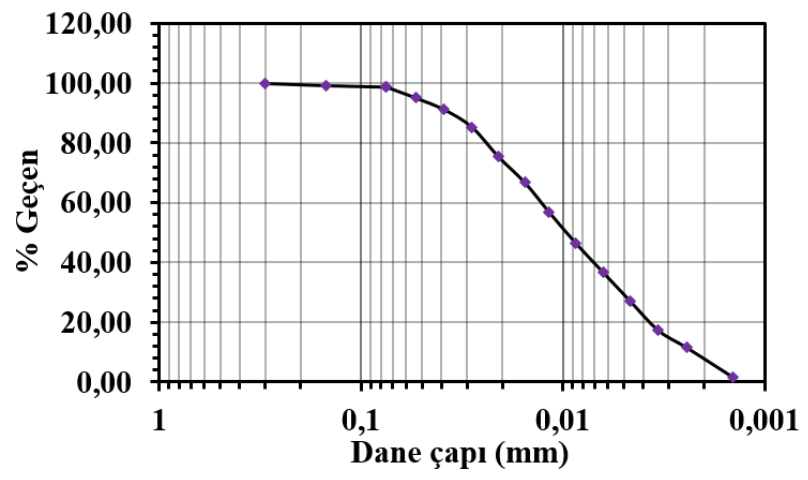

Şekil 1. Granülometri eğrisi

Zeminin güçlendirilmesi amacı ile 6 mm uzunluğa ve 13-15 $\mu \mathrm{m}$ çapa sahip cam lif malzemesi kullanılmıştır (Şekil 2). Cam life ait mekanik ve fiziksel özellikler üretici firmadan alınmış olup bu özellikler Tablo 2'de verilmiştir.

Tablo 1. Kil zeminin özellikleri

\begin{tabular}{|c|c|}
\hline Özellikler & Değer \\
\hline Likit limit (\%) & 35 \\
\hline Plastik limit (\%) & 19 \\
\hline Plastisite indisi (\%) & 16 \\
\hline Max. kuru yoğunluk (gr/cm $\left.{ }^{3}\right)$ & 1,75 \\
\hline Optimum su muhtevası (\%) & 15 \\
\hline Özgül ağırlık & 2,73 \\
\hline No \#200 Elek Altı Malzeme (\%) & 98,8 \\
\hline Zemin Sınıfı: Düşük Plastisiteli Kil (CL) \\
\hline
\end{tabular}

\subsection{Numunelerin Hazırlanması}

Literatürde liflerin segregasyonundan kaçınmak, zemin içerisinde liflerin üniform dağılmasına ve izotropik yönlenmesine imkan tanımak için numunelerin hazırlanması aşamasında farklı yöntemler dikkate alınmıştır (Murray vd. 2000, Marandi vd. 2008, Sadeghi ve Beigi 2014, Soğanc1 2015, Gao vd. 2017, Motiram vd. 2018, Tran vd. 2018, Liu vd. 2020). Bu yöntemlerden en uygun olanının seçilmesi, esasen lifin özelliklerine ve zemin türüne bağlı olarak değişmektedir (Falorca ve Pinto 2011). Lif-zemin karışımlarının oluşturulmasında liflerin zemin içerisine homojen dağılmasını sağlamak, liflerin belirli bölgelerde yoğunlaşmasını ve topaklanmaların oluşmasını önlemek gerekmektedir. Homojen lif-zemin karışımlarının oluşturulması büyük ölçüde, zemin ve lif malzemelerinin karıştırılması aşamasında kullanılan karıştırma yöntemine bağlıdır. Literatürde el ile karıştırma yöntemi, küçük ölçekli laboratuvar işlerinde yaygın bir şekilde kullanılmakta ve bu karıştırma yöntemi ile liflerin dağılımının gözlenebilmesi bu yöntemin bir avantajı olarak karşımıza çıkmaktadır (Yetimoğlu ve Salbaş 2003, Falorca ve Pinto 2011, Choo vd. 2017, Sujatha vd. 2020). Sonuç olarak bu çalışma kapsamında lif-zemin karışımlarının hazırlanması aşamasında el ile karıştırma yöntemi 
Tablo 2. Cam lifin özellikleri

\begin{tabular}{|c|c|c|c|c|c|}
\hline Lif türü & $\begin{array}{c}\text { Özgül Ağırlık } \\
\left(\mathrm{gr} / \mathrm{cm}^{3}\right)\end{array}$ & $\begin{array}{c}\text { Çekme Mukavemeti } \\
(\mathrm{GPa})\end{array}$ & $\begin{array}{c}\text { Elastisite Modülü } \\
(\mathrm{GPa})\end{array}$ & $\begin{array}{c}\text { Lif Çap1 } \\
(\mu \mathrm{m})\end{array}$ & $\begin{array}{c}\text { Lif Uzunluğu } \\
(\mathrm{mm})\end{array}$ \\
\hline Cam & 2,60 & 3,4 & 77 & $13-15$ & 6 \\
\hline
\end{tabular}

tercih edilmiştir. Karışımda kullanılacak lif miktarının belirlenmesi için Eşitlik (1)'de verilen gravimetrik lif yüzdesi kullanılmıştır.

$$
P_{f}=\frac{M_{f}}{M_{k}}
$$

Burada Pf; ağırlıkça lif yüzdesini, Mf; liflerin ağırlığını, Mk; zeminin kuru ağırlığını temsil etmektedir.

Cam lif takviyesinin kil zeminin kayma mukavemeti parametreleri üzerindeki etkilerinin araştırılması amacıyla kuru zemin içerisine ağırlıkça $\% 1, \% 1,5$ ve $\% 2$ miktarlarında lif ilave edilmiştir. Lif-zemin karışımına su muhtevasının etkilerini de gözlemleyebilmek için bu çalışma kapsamında OSİ ve OSİ \pm 2 miktarlarında su kullanılmıştır. Daha önceden etüvde kurutulmuş zemin içerisine ilk olarak ilgili miktarda cam lif malzemesi ilave edilmiş ve karıștırılmıştır. Daha sonra hazırlanan bu karışıma $\% 13, \% 15$ ve $\% 17$ oranlarında su eklenmiş ve liflerin zemin içerisinde homojen dağılması sağlanana kadar karışım el ile karıştırılmıştır. Her bir karışım $60 \mathrm{~mm}$ x $60 \mathrm{~mm}$ x $20 \mathrm{~mm}$ boyutlara sahip bir ring içerisinde maksimum kuru birim hacim ağırlık (MKBHA) değerinde sıkıştırılarak numuneler hazırlanmıştır. Hazırlanan numuneler direkt kesme deneyinde kırılmış ve lif miktarı ile su içeriğinin zeminin kayma mukavemeti özellikleri üzerindeki etkileri araștırılmıştır.

\subsection{Deney Prosedürü}

Direkt kesme deneyinde kırılmak üzere farklı su ve lif içeriklerine sahip, $60 \mathrm{~mm}$ x $60 \mathrm{~mm}$ x $20 \mathrm{~mm}$ boyutlardaki lifzemin kompozit numuneleri MKBHA değerinde sıkıştırılarak hazırlanmıştır. Daha sonra hazırlanan her bir numune 60,120 ve $240 \mathrm{kPa}$ büyüklüğünde düşey gerilme altında, $1 \mathrm{~mm} / \mathrm{dk}$ kesme hızında \%15 birim boy değişimine kadar kesilmiştir. $\mathrm{Bu}$ çalışmada kullanılan direkt kesme deneyi cihazı Şekil 3'te, kesilen numuneler ise Şekil 4'te gösterilmiştir.

\section{Bulgular ve Tartışma}

Cam lif ile güçlendirilmiş kil zeminin pik kayma mukavemeti, pik dayanıma karşılık gelen içsel sürtünme açısı ve kohezyon değerleri direkt kesme deneyinde araştırılmıştır. Pik kayma mukavemetine karşılık gelen kohezyon ve içsel sürtünme açısı değerlerinin lif içeriğine ve su muhtevasına bağlı değişimi sırasıyla Şekil 5a ve Şekil 5b'de gösterilmiştir. Şekil 5a'ya bakıldığında genel olarak su muhtevasının artması ile kohezyon değerinin azaldığı görülmektedir. $\% 13$ su muhtevasında hazırlanan numunelerde kohezyon değeri, lif içeriğinin \%1'e kadar artması ile artmakta, \%1'den daha büyük lif içeriklerinde ise azalmaktadır. OSI'ye sahip numunelerde ise en yüksek kohezyon değeri \%1,5 lif ile güçlendirilmiş numunelerde meydana gelmektedir. Buna karşılık \%17 su muhtevası için lif içeriğinin artması ile kohezyon değeri sürekli artmaktadır. \%13 su muhtevası ve \%1 lif içeriğinde hazırlanan lif-zemin kompozitinin kohezyon değerinin katkısız numuneye nispeten \%10 arttığı, OSI değerinde \%1,5 lif ile güçlendirilmiş numunede bu artışın $\% 5$ olduğu gözlenmektedir. Şekil $5 b$ incelendiğinde $\% 1$ 'den daha küçük lif içeriklerinde su muhtevasının artması ile içsel sürtünme açısının azaldığı, \%1'den büyük lif içeriklerinde ise en yüksek içsel sürtünme açısının \%15 su muhtevasına sahip numunelerde meydana geldiği görülmektedir. $\% 13$ su muhtevasına sahip numunelerde içsel sürtünme açısı, lif içeriğinin \%1'e kadar artması ile artmakta, \%1'den büyük lif içeriklerinde ise azalmaktadır. \%15 su muhtevası için içsel sürtünme açısı değeri lif miktarının \%1,5'e kadar artması ile artmakta, \%1,5'ten daha büyük lif içeriklerinde ise azalmaktadır. Öte taraftan \%17 su muhtevasına sahip numunelerde ise lif içeriğinin artması ile içsel sürtünme açısının sürekli arttığı görülmektedir. \%13 su muhtevası ve \%1 lif içeriğinde hazırlanan lif-zemin kompozitinin kohezyon ve içsel sürtünme açısı değerlerinin katkısız numuneye nispeten sırasıyla \%10 ile \%4 arttığ 1 , OSİ miktarında su ve $\% 1,5$ oranında lif ile güçlendirilmiş numunede ise bu artışların sırasıyla $\% 5$ ile \%22 olduğu gözlenmektedir. Sonuç olarak cam lif-kil karışımının kullanılmasına karar verilen uygulama projelerinde karışıma katılacak su miktarının belirlenmesinde amaca uygun olan su içeriği seçilebilir. Örneğin zemini güçlendirmedeki amaç kohezyonu arttırmak ise kil-lif karışımında OSİ değerinden daha düşük su içeriği kullanılabilir. Buna karşılık amaç içsel sürtünme açısını arttırmak ise lif-kil karışımı OSİ değerinde hazırlanabilir. Şekil 6'da kayma mukavemetinin su muhtevasına, normal gerilmeye ve lif miktarına bağlı değişimini gösteren grafikler verilmiştir. Şekil 6'da verilen grafikler, genel olarak su muhtevasının artması ile kayma mukavemetinin azaldığını göstermektedir. Lif ile güçlendirilmiş zeminlerde, lif-zemin kompoziti yük aldığı esnada zemin içerisinde meydana gelen

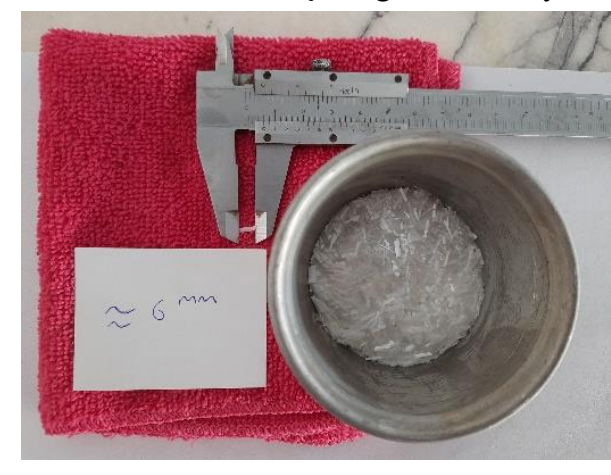

Şekil 2. Cam lif

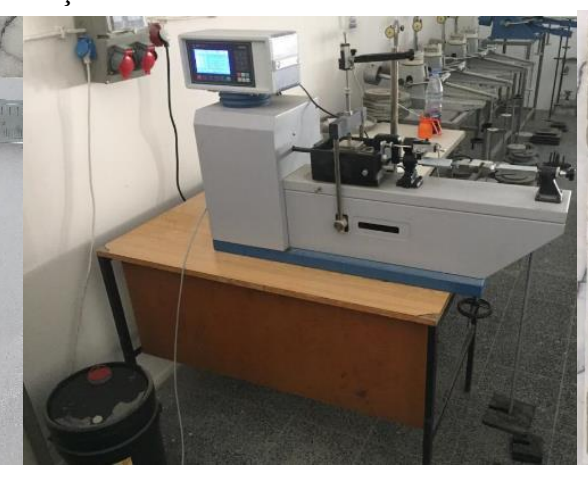

Şekil 3. Kesme kutusu cihazı

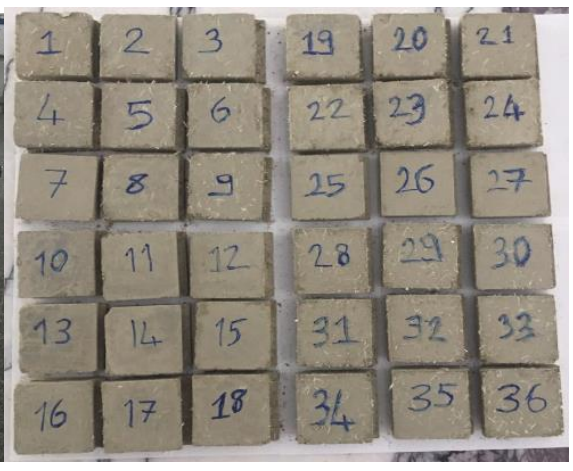

Şekil 4. Kesilen numuneler 
(a)

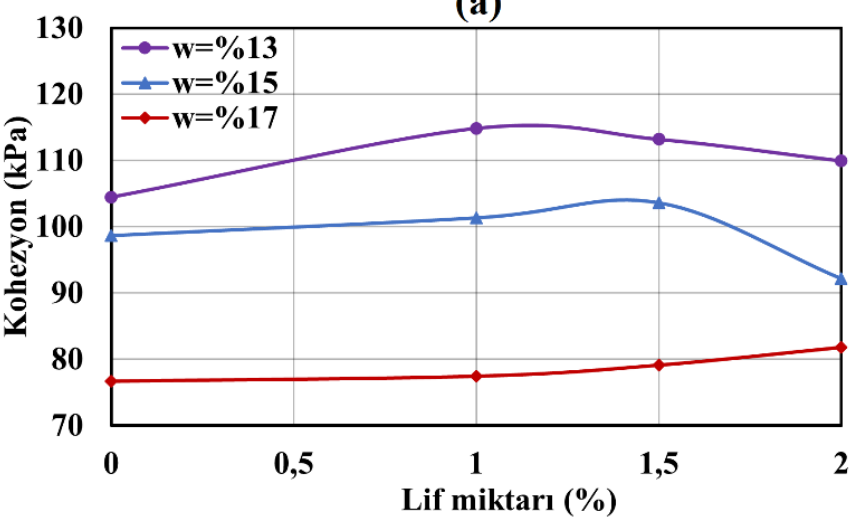

(b)

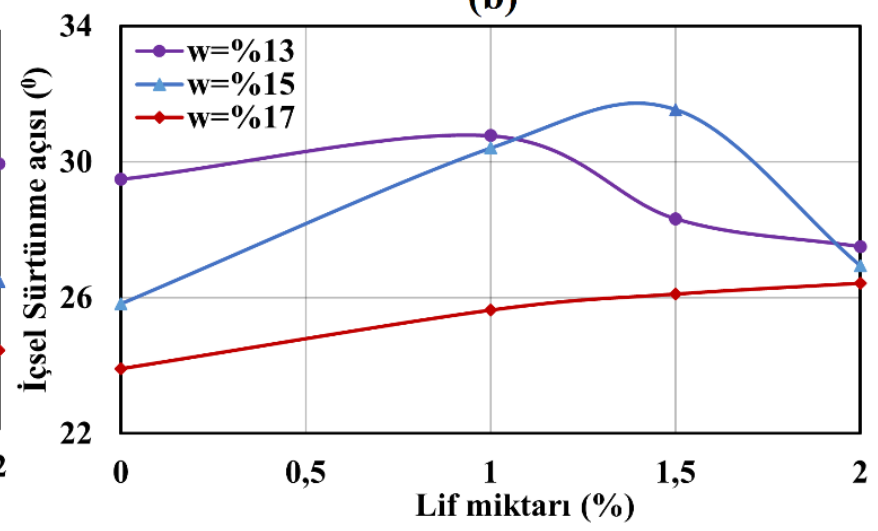

Şekil 5. Farklı su içerikleri için lif miktarlarına karşılık (a) kohezyonun (b) içsel sürtünme açısının değişimi

(a)

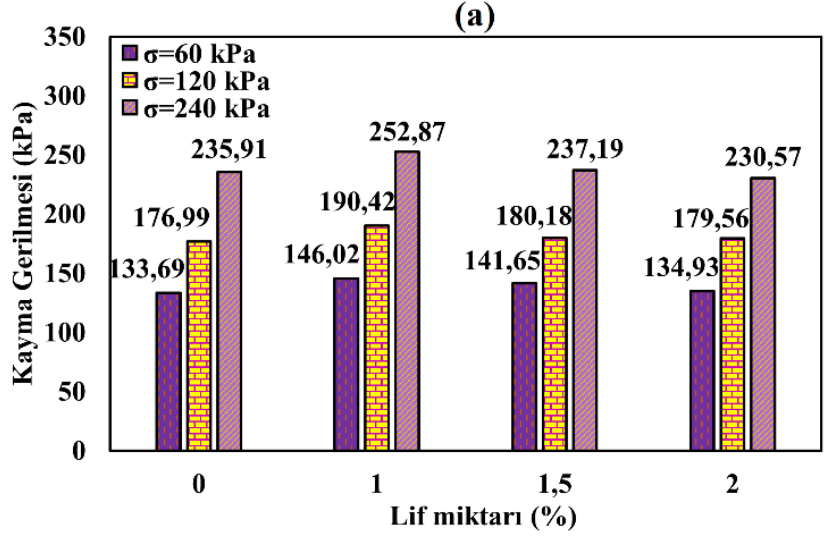

(b)

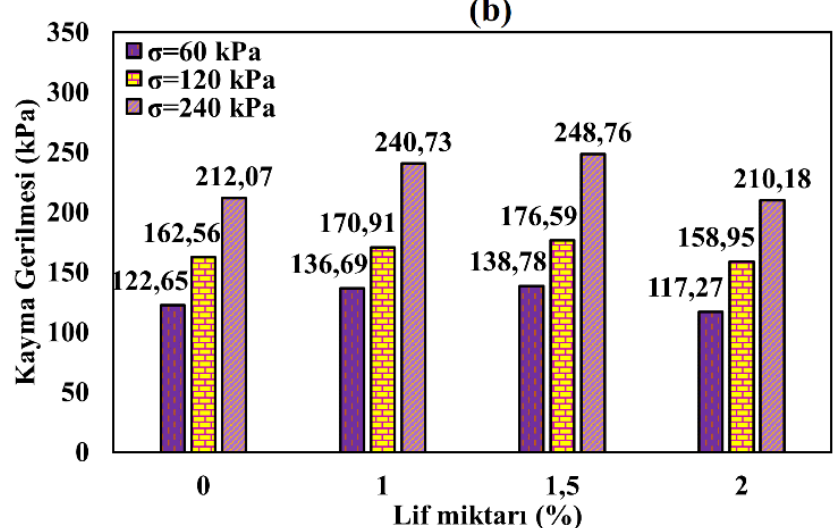

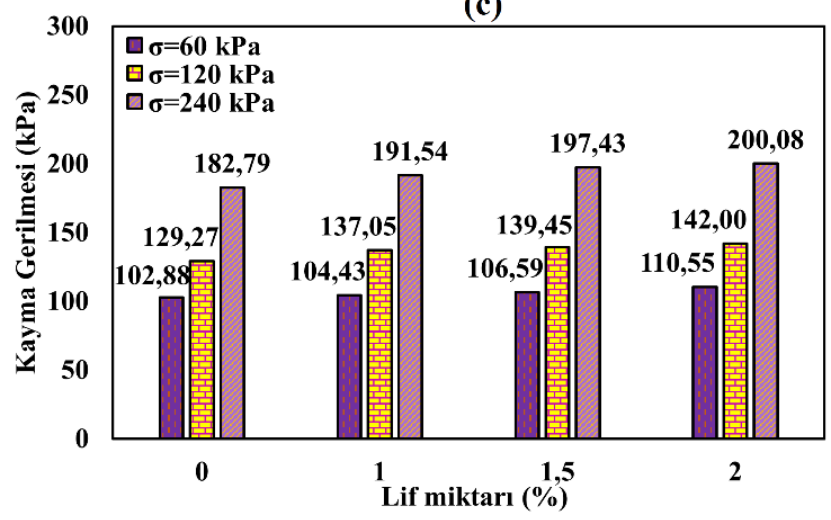

Şekil 6. (a) \%13, (b) \%15, (c) \%17 su içeriklerinde hazırlanan numunelerin kayma mukavemeti üzerine lif miktarı ve normal gerilmenin etkisi

kayma gerilmeleri liflerdeki çekme dirençlerini mobilize etmekte ve böylece zeminin dayanımı artmaktadır (Jamshidi vd 2010). Lifler ile kil zemin arasındaki adezyonun fazla olması durumunda güçlendirmenin etkisi artmaktadır. Lif ile güçlendirilmiş kil zeminde yüksek su içeriklerinde zemin daneleri ile lifler arasındaki adezyon azalmakta ve bunun bir sonucu olarak lifzemin kompozitinin kayma mukavemeti azalmaktadır (Arabani ve Haghsheno 2020). Bu durum Şekil 6'da su içeriğinin artması sonucu kayma mukavemetinde meydana gelen azalışı açıklamaktadır.

Cam lifle güçlendirilmiş kil zeminin kayma mukavemetindeki optimum artışın $\% 13$ ve $\% 15$ su içeriklerinde sırasıyla \%1 ve \%1,5 lif kullanılması durumunda elde edildiği sonucuna varılmıştır. Buna karşılık \%17 su muhtevasına sahip numunelerde kayma mukavemeti artışı açısından optimum bir lif içeriğgi gözlenmemiştir. Ayrıca \%13 ve \%17 su muhtevasına sahip lif takviyeli kil zeminde kayma mukavemeti artışı üzerine normal gerilmenin önemli bir etkisinin olmadığı görülmüştür. Yine de $\% 13$ ve $\% 17$ su içeriğine sahip numunelerde kayma mukavemetinde en yüksek artışların sırasıyla $60 \mathrm{kPa}$ ve $120 \mathrm{kPa}$ normal gerilme altında meydana geldiği gözlenmiştir. Buna karşılık OSİ değerinde su içeren numunelerde ise daha yüksek normal gerilme altında kayma mukavemetinde dikkate değer artışlar meydana gelmiştir.

\section{Sonuçlar}

$\mathrm{Bu}$ çalışmada düşük plastisiteli kil zeminin kayma mukavemeti üzerine cam lif ilavesinin, su muhtevasının ve normal gerilmenin etkileri direkt kesme deneyi vasıtasıyla 
incelenmiştir. Cam lifle güçlendirilmiş düşük plastisiteli kilin pik kayma mukavemeti, kohezyon ve içsel sürtünme açısı değerlerini su muhtevası ve lif içeriğinin dikkate değer miktarda etkilediği gözlemlenmiş olup, deneylerden elde edilen sonuçlar aşağıda verilmiştir:

Kil zeminin kohezyon ve içsel sürtünme açısı değerlerinde en yüksek iyileşmenin meydana geldiği lif içeriği, \%13 su muhtevası için $\% 1, \% 15$ su içeriği içinse $\% 1,5$ olarak belirlenmiştir. \%17 su muhtevasına sahip zeminde lif içeriğinin artması ile kohezyon değerinin sürekli arttığı görülmüştür.

$\mathrm{Su}$ muhtevası ve lif içeriğine karşılık kohezyon ve içsel sürtünme açısında meydana gelen değişime bağlı olarak kil zeminde en yüksek kayma mukavemeti değerlerini veren lif içerikleri, $\% 13$ ve $\% 15$ su muhtevaları için sırasıyla $\% 1$ ve $\% 1,5$ olarak bulunmuştur.

OSİ-2, OSİ ve OSİ+2 su içeriklerinde hazırlanan lif-kil kompozit numunelerinde kayma mukavemeti artışlarının en fazla olduğu normal gerilme değerlerinin sirasiyla 60,120 ve $240 \mathrm{kPa}$ olduğu gözlenmiştir.

$\mathrm{Su}$ içeriğinin artması ile zemin daneleri ile lifler arasında meydana gelen adezyonun azalmasından ötürü genel olarak hem güçlendirilmemiş hem de güçlendirilmiş kil zeminin kayma mukavemetinin azaldığ 1 sonucu elde edilmiştir.

En yüksek içsel sürtünme açısı değerinin OSI'ne ve \%1,5 oranında life sahip kil zeminde, en yüksek kayma mukavemeti ve kohezyon değerlerinin ise \%13 su muhtevasına ve \%1 lif içeriğine sahip kil zeminde meydana geldiği sonucuna ulaşılmıştır.

\section{Kaynaklar}

Abdeldjouad, L., Asadi, A., Ball, R. J., Nahazanan, H., \& Huat, B. B. (2019). Application of alkali-activated palm oil fuel ash reinforced with glass fibers in soil stabilization. Soils and Foundations, 59(5), 1552-1561.

Anagnostopoulos, C. A., Tzetzis, D., \& Berketis, K. (2013). Shear strength behaviour of polypropylene fibre reinforced cohesive soils. Geomechanics and Geoengineering, 9, 241251.

Arabani, M., \& Haghsheno, H. (2020). The effect of water content on shear and compressive behavior of polymeric fiberreinforced clay. SN Applied Sciences, 2(11), 1-12.

Asadollahi, F., \& Dabiri, R. (2017). Effects of Glass Fiber Reinforced Polymer on Geotechnical Properties of Clayey Soil. Journal of Structural Engineering and Geo-Techniques, 7(2), 73-83.

Baruah, H. (2015). Effect of glass fibers on red soil. International Journal of Advanced Technology in Engineering and Science, 3(1), 217-223.

Choo, H., Yoon, B., Lee, W., \& Lee, C. (2017). Evaluation of compressibility and small strain stiffness characteristics of sand reinforced with discrete synthetic fibers. Geotextiles and Geomembranes, 45(4), 331-338.

Estabragh, A. R., Bordbar, A. T., \& Javadi, A. A. (2011). Mechanical behaviour of a clay soil reinforced with nylon fibers. Geotechnical and Geological Engineering, 29, 899908.

Falorca, I. M. C. F. G., \& Pinto, M. I. M. (2011). Effect of short, randomly distributed polypropylene microfibres on shear strength behaviour of soils. Geosynthetics International, 18(1), 2-11.
Gao, L., Zhou, Q., Yu, X., Wu, K., \& Mahfouz, A. H. (2017). Experimental study on the unconfined compressive strength of carbon fiber reinforced clay soil. Marine Georesources \& Geotechnology, 35(1), 143-148.

Gray, D. H., \& Maher, M. H. (1989). Admixture stabilization of sands with discrete, randomly distributed fibers. In Proc. of the 12th International Conference on Soil Mechanics and Foundation Engineering, August 13-18, Rio de Janeiro, Brazil.

Jamshidi, R., Towhata, I., Ghiassian, H., \& Tabarsa, A. R. (2010). Experimental evaluation of dynamic deformation characteristics of sheet pile retaining walls with fiber reinforced backfill. Soil Dynamics and Earthquake Engineering, 30(6), 438-446.

Liu, C., Lv, Y., Yu, X., \& Wu, X. (2020). Effects of freeze-thaw cycles on the unconfined compressive strength of straw fiberreinforced soil. Geotextiles and Geomembranes, 48(4), 581590.

Maher, H., \& Gray, H. (1990). Static response of sand reinforced with randomly distributed fibers. Journal of Geotechnical Engineering ASCE, 116(11), 1661-1677.

Marandi, M., Bagheripour, H., Rahgozar, R., and Zare, H. (2008). Strength and ductility of randomly distributed palm fibers reinforced silty-sand soils. American Journal of Applied Sciences, 5(3), 209-220.

Motiram, P. V., Rohit, C., Tushar, K., Ayushi, C., Bhushan, G., and Deepali, C. (2018). Study of basalt fiber on compaction characteristics of black cotton soil. International Journal for Research in Engineering Application and Management (IJREAM), 850-853.

Murray, J. J., Frost, J. D., \& Wang, Y. (2000). Behavior of a sandy silt reinforced with discontinuous recycled fiber inclusions. Transportation Research Record, 1714(1), 9-17.

Sadeghi, M. M., \& Beigi, F. H. (2014). Dynamic behavior of reinforced clayey sand under cyclic loading. Geotextiles and Geomembranes, 42(5), 564-572.

Saha, H. S., \& Bhowmik, D. (2018). Effect of glass fiber on shear strength of soil. Key Engineering Materials, 775, 603-609.

Soğanc1, A. S. (2015). The effect of polypropylene fiber in the stabilization of expansive soils. International Journal of Geological and Environmental Engineering, 9(8), 994-997.

Sujatha, E. R., Atchaya, P., Darshan, S., \& Subhashini, S. (2020). Mechanical properties of glass fibre reinforced soil and its application as subgrade reinforcement. Road Materials and Pavement Design, 21, 1-12.

Tran, K. Q., Satomi, T., \& Takahashi, H. (2018). Effect of waste cornsilk fiber reinforcement on mechanical properties of soft soils. Transportation Geotechnics, 16, 76-84.

Yetimoğlu, T., \& Salbaş, O. (2003). A study on shear strength of sands reinforced with randomly distributed discrete fibers. Geotextiles and Geomembranes, 21(2), 103-110. 